\title{
Perineuronal Oligodendrocytes Protect against Neuronal Apoptosis through the Production of Lipocalin-Type Prostaglandin D Synthase in a Genetic Demyelinating Model
}

\author{
Masako Taniike, ${ }^{1 *}$ Ikuko Mohri, ${ }^{*}$ Naomi Eguchi, ${ }^{2,3 *}$ Carsten T. Beuckmann, ${ }^{2}$ Kinuko Suzuki, ${ }^{4}$ and \\ Yoshihiro Urade ${ }^{2,3}$ \\ ${ }^{1}$ Department of Developmental Medicine (Pediatrics), D-5 Osaka University Graduate School of Medicine, Osaka 565- \\ 0871, Japan, ${ }^{2}$ Department of Molecular Behavioral Biology and ${ }^{3}$ Core Research for Evolutional Science and Technology, \\ Japan Science and Technology Corporation, Osaka Bioscience Institute, Osaka 565-0874, Japan, and ${ }^{4}$ Department of \\ Pathology and Laboratory Medicine, and Neuroscience Center, School of Medicine, University of North Carolina at \\ Chapel Hill, Chapel Hill, North Carolina 27599-7525
}

The genetic demyelinating mouse "twitcher" is a model of the human globoid cell leukodystrophy, caused by galactosylceramidase (GALC) deficiency. Demyelination in the twitcher brain is secondary to apoptotic death of oligodendrocytes (OLs). Lipocalin-type prostaglandin (PG) D synthase (L-PGDS), a protein expressed in mature OLs, was progressively upregulated in twitcher OLs; whereas expression of OL-associated proteins such as carbonic anhydrase II, myelin basic protein, and myelin-associated glycoprotein was downregulated during demyelination in twitcher brains. The upregulation of L-PGDS was more remarkable in perineuronal OLs than in interfascicular OLs. A larger number of L-PGDS-positive OLs was found in selected fiber tracts of twitcher brains where fewer apoptotic cells were detected. The distribution of L-PGDS-positive OLs was inversely related to the severity of demyelination, as as- sessed by accumulation of scavenger macrophages. Mice doubly deficient for L-PGDS and GALC disclosed a large number of apoptotic neurons, which were never seen in twitcher brains, in addition to an increased number of apoptotic OLs. A linear positive correlation was observed between the population of L-PGDS-positive OLs in the twitcher brain and the ratio of apoptotic nuclei in the double mutant versus those in the twitcher, suggesting a dose-dependent effect of L-PGDS against apoptosis. These lines of evidence suggest that L-PGDS is an anti-apoptotic molecule protecting neurons and OLs from apoptosis in the twitcher mouse. This is a novel example of OL-neuronal interaction.

Key words: prostaglandin $D_{2}$; lipocalin-type prostaglandin $D$ synthase; twitcher; oligodendrocyte; demyelination; galactosylceramidase; apoptosis
Prostaglandin (PG) $\mathrm{D}_{2}$ is a major $\mathrm{PG}$ in the CNS of rats, mice, and humans, and functions as a neuromodulator of several central actions, such as regulation of the sleep-wake cycle (Urade and Hayaishi, 1999, 2000b; Hayaishi and Urade, 2002), body temperature, hormone release, and pain responses (Eguchi et al., 1999). In the $\mathrm{CNS}, \mathrm{PGD}_{2}$ is mainly synthesized by lipocalin-type PGD synthase (L-PGDS; Urade et al., 1985a; Ujihara et al., 1988). Although L-PGDS is mainly expressed in the leptomeningeal

\footnotetext{
Received Oct. 31, 2001; revised March 21, 2002; accepted April 3, 2002.

This work was supported in part by research grants from the Ministry of Education, Culture, Sports, Science, and Technology of Japan (09670806, M.T.; 13557016, N.E.; 12558078, Y.U.), Japan Science and Technology Corporation (N.E. and Y.U.), Suntory Institute for Bioorganic Research (N.E.), Takeda Science Foundation (N.E. and Y.U.), Yamanouchi Foundation for Research on Metabolic Disorders (N.E.), the National Institutes of Health United States Public Health Service (NS-24453 and HD-03110, K.S), and Osaka City. We thank Kiyokazu Momose (Oriental Yeast Co., Ltd., Tokyo, Japan) for supplying CMS Sprout diet, Dr. Wendy Cammer (Department of Neuroscience, Albert Einstein College of Medicine) for a generous gift of anti-CA II antibody, Shigeko Matsumoto for immunohistochemistry, Daisuke Irikura for Northern blot analysis, and Kosuke Aritake for measurement of psychosine. We also thank Dr. Takashi Inui (Osaka Bioscience Institute) and Dr. Masahiko Takada (Tokyo Metropolitan Institute for Neuroscience) for their comments during the preparation of this manuscript. We are grateful to Dr. Osamu Hayaishi (Osaka Bioscience Institute) and Dr. Shintaro Okada (Osaka University), for their encouragement of this study.

*M.T., I.M., and N.E. contributed equally to this work.

Correspondence should be addressed to Yoshihiro Urade, Osaka Bioscience Institute, 6-2-4 Furuedai, Suita City, Osaka 565-0874, Japan. E-mail: uradey@obi.or.jp.

C. T. Beuckmann's present address: Howard Hughes Medical Institute at University of Texas Southwestern Medical Center, Dallas, TX 75390-9050.

Copyright (C) 2002 Society for Neuroscience $\quad 0270-6474 / 02 / 224885-12 \$ 15.00 / 0$
}

cells (Urade et al., 1993; Beuckmann et al., 2000), immunohistochemistry and in situ hybridization revealed that L-PGDS is also produced in oligodendrocytes (OLs) after commencement of myelination in rats (Urade et al., 1987, 1993; Garcia-Fernandez et al., 1997; Beuckmann et al., 2000), mice (Eguchi et al., 1999), and humans (Blodorn et al., 1996). Because L-PGDS is not expressed in Schwann cells of the peripheral nerve system, this protein is a specific marker for mature OLs (Urade et al., 1985b).

The twitcher mouse (C57BL/6J-GALC $C^{t w i / t w i}$ ), a homozygote for a nonsense point mutation of the galactosylceramidase (GALC) gene, is a model of the human genetic demyelinating disease called globoid cell leukodystrophy (Duchen et al., 1980; Wenger et al., 2000). The cause of demyelination in twitcher mice has been suggested to be the result of an accumulation of the toxic metabolite psychosine (Igisu and Suzuki, 1984b; Suzuki and Taniike, 1995), leading to the dysfunction of myelin-forming cells, i.e., OLs and Schwann cells. Because demyelination in the twitcher brain progresses in an orderly manner (Taniike and Suzuki, 1994), this mutant is a valuable model for investigating the molecular events occurring in OLs during the demyelinating process. The expression of OL markers, such as myelin basic protein, myelin-associated glycoprotein, and proteolipid protein, all decreased after the commencement of demyelination in the twitcher brain (Taniike et al., 1998). We previously reported that the depletion of OLs in the twitcher brain is caused by apoptosis (Taniike et al., 1999). 
Because L-PGDS is expressed in normal mature OLs, we investigated L-PGDS expression in the twitcher brain during the demyelination process. Unexpectedly, we found that expression of L-PGDS was upregulated in twitcher brains. Furthermore, we found that the distribution of L-PGDS ${ }^{+}$OLs and the severity of demyelination were in inverse relationship. Thus, we hypothesized that upregulation of L-PGDS may suppress apoptosis of OLs, since demyelination is secondary to the apoptosis of OLs in the twitcher brains. We finally confirmed the anti-apoptotic role of L-PGDS by generating double-mutant, L-PGDS-deficient ( $L$ $\left.P G D S^{-/-}\right)$twitcher $\left(G A L C^{t w i / t w i}\right)$ mice.

\section{MATERIALS AND METHODS}

Animals. All animal experiments were performed according to the Japanese Law for the Protection of Experimental Animals and also conformed to the regulations issued by the National Institutes of Health and the Society for Neuroscience. Twitcher heterozygous pairs $\left(G A L C^{t w i /+}\right.$, the inbred C57BL/6J-twi strain) were originally purchased from Jackson Laboratory (Bar Harbor, ME), and the mutation was maintained by interbreeding of known heterozygous mice. $L-P G D S^{-1-}$ mice were generated through gene targeting technology (Eguchi et al., 1999) and backcrossed to the inbred C57BL/6J strain. Southern blot and/or PCR analysis of DNA prepared from clipped tails was conducted as previously described (Sakai et al., 1996; Eguchi et al., 1999). For the detection of wild-type or mutant alleles of $L-P G D S, 5^{\prime}$ primer (P1: 5'-TGTCAGGAATGTGGTATGCTC-3') was used together with either P2 (5'AATACAGCTTTCTTCTCCCGGAAC-3') or P3 (5'-GTAGCCGGATCAAGCGTATGC- $3^{\prime}$ ) primers.

For generation of double mutant mice $\left(L-P G D S^{-/-} G A L C^{t w i t t w i}\right)$, $L-P G D S^{-1-}$ C57BL/6J offspring $\left(L-P G D S^{-/-} G A L C^{+/+}\right)$were mated with $L-P G D S^{+/+} G A L C^{t w i /+}$ to create F1 $\left(L-P G D S^{+/-} G A L C^{+/+}\right.$and $L-P G D S^{+/-} G A L C^{t w i /+}$ ). Of the $\mathrm{F} 2$ litters produced by mating of F1, $L-P G D S^{-/-} G A L C^{t w i /+}$ were mated with each other to produce $L-P G D S^{-1-} G A L C^{t w i / t w i}$ F3. Control $L-P G D S^{+/+} G A L C^{t w i / t w i}$ F3 were produced by mating $L-P G D S^{+/+} G A L C^{t w i /+} \mathrm{F} 2$ mice. These two types of F3 mice thus produced were subjected to the analysis. The frequency of the each genotype in all generations conformed to Mendelian inheritance patterns.

Materials. Rabbit polyclonal and rat monoclonal anti-mouse L-PGDS antibodies were raised and purified as described previously (Eguchi et al., 1999). Preabsorbed antibody was prepared by incubation of polyclonal antibody with an excess amount of purified recombinant L-PGDS. These antibodies were used at a dilution of 1:1000. The other antibodies used were as follows: rabbit polyclonal anti-mouse pi-form of glutathione $S$-transferase (pi-GST) antibody (1:1000; Biotrin International, Dublin, Ireland), rabbit polyclonal anti-mouse carbonic anhydrase II (CA II) antibody (1:1000; a generous gift from Dr. W. Cammer, Department of Neuroscience, Albert Einstein College of Medicine), rabbit polyclonal anti-cow glial fibrillary acidic protein (GFAP) antibody (prediluted; Dako, Glostrup, Denmark), rabbit polyclonal anti-S-100 antibody (1; 1000; DAKO), rat monoclonal anti-mouse F4/80 antibody (1:400; Serotec, Oxford, UK), and mouse monoclonal anti-rat microtubule-associated protein 2 (MAP2) antibody (1:200; Sigma, St. Louis, MO). Biotinylated Ricinus communis-agglutinin-1 (RCA-1; $50 \mu \mathrm{g} / \mathrm{ml}$ ) was purchased from Vector Laboratories (Burlingame, CA).

$R N A$ isolation, electrophoresis, and hybridization. Under deep ether anesthesia, mice were killed at postnatal day 15 (P15), P20, P30, and P45. Entire brains or brains divided into cerebellum and cerebrum were used. When indicated, leptomeninges and choroid plexus were removed under a dissecting microscope. The brains were quickly frozen in liquid nitrogen, with subsequent total RNA isolation by the guanidinium thiocyanate-phenol-chloroform method (Chomczynski and Sacchi, 1987). Total RNA $(10 \mu \mathrm{g})$ was electrophoresed in an agarose gel, transferred to Zeta Probe nylon membranes (Bio-Rad Laboratories, Hercules, CA), and hybridized with ${ }^{32} \mathrm{P}$-labeled cDNA probes specific for mouse L-PGDS (Eguchi et al., 1999), mouse CA II, or mouse glyceraldehyde3-phosphate dehydrogenase (G3PDH). The blots were visualized by autoradiography with Kodak XAR-5 film and an intensifying screen. The relative amount of each transcript was estimated by quantifying the associated radioactivity with the BAS-2000 system (Fuji film, Tokyo, Japan).

In situ hybridization. Paraffin sections of mouse brains were hybridized with ${ }^{35} \mathrm{~S}$ - or digoxigenin-labeled antisense riboprobe for mouse L-PGDS as previously described (Urade et al., 1993; Gerashchenko et al., 1998). Signal specificity was assessed by incubation of adjacent sections with the labeled sense riboprobe.

Measurement of L-PGDS activity and psychosine content in brain. L-PGDS activity was determined in mouse brains with $40 \mu \mathrm{M}\left[1-{ }^{14} \mathrm{C}\right]$ $\mathrm{PGH}_{2}$ in the presence of $1 \mathrm{~mm}$ dithiothreitol (Urade et al., 1985a). Protein concentrations were determined by use of bicinchoninic acid reagent (Pierce, Rockford, IL) with bovine serum albumin used as the standard by following the manufacturer's protocol. The level of psychosine in mouse brains was measured by the method previously described (Igisu and Suzuki, 1984a).

\section{Immunohistochemistry, lectin histochemistry, and terminal deoxynucleotidyl transferase-mediated biotinylated UTP nick end labeling staining}

We used four mice per genotype for each age for immunohistochemical analysis for L-PGDS. Under deep ether anesthesia, mice were briefly perfused through the left cardiac ventricle with physiological saline followed by $4 \%$ paraformaldehyde in $0.1 \mathrm{M}$ phosphate buffer (PB; $\mathrm{pH}$ 7.4). Their brains were immediately removed, postfixed overnight in the same solution, and processed for paraffin embedding.

The immunohistochemical results with a polyclonal rabbit antibody and a monoclonal rat antibody against mouse L-PGDS (Eguchi et al., 1999) were basically the same. Therefore, monoclonal antibody was used in most cases because of lower background staining. Deparaffinized and hydrated sections (5- $\mu \mathrm{m}$-thick) were preincubated with $0.3 \% \mathrm{H}_{2} \mathrm{O}_{2}$ in methanol followed by PBS containing $0.2 \%$ Triton X-100. After pretreatment with trypsin for $15 \mathrm{~min}$, the sections were sequentially incubated with L-PGDS antibody, appropriate biotinylated secondary antibody, and avidin-biotin complex (ABC; Vector Laboratories) according to the manufacturer's protocol. Immunoreactivity was visualized with $0.03 \%$ $\mathrm{H}_{2} \mathrm{O}_{2}$ solution in $50 \mathrm{~mm}$ Tris- $\mathrm{HCl}, \mathrm{pH}$ 7.6, containing $0.05 \%$ diaminobenzidine (Dotite, Kumamoto, Japan).

For double immunostaining, anti-pi-GST/CA II, GFAP/S-100, and F4/80 antibodies were used to identify OLs, astrocytes, and microgliamacrophages, respectively (Tansey and Cammer, 1991; Toyooka et al., 1993; Taniike and Suzuki, 1995). Deparaffinized sections were incubated at $4^{\circ} \mathrm{C}$ overnight with one of these primary antibodies together with anti-mouse L-PGDS antibody. Rat anti-L-PGDS antibody was used in all cases except for the staining combined with F4/80, in which case rabbit L-PGDS antibody was used. Sections were then reacted with Texas Red-conjugated anti-rabbit IgG antibody $(2 \mu \mathrm{g} / \mathrm{ml}$; ICN Biomedicals, Aurora, $\mathrm{OH}$ ) and biotin-conjugated anti-mouse $\mathrm{IgG}$ antibody (Vector Laboratories) for $2 \mathrm{hr}$, followed by FITC-conjugated avidin D $(2 \mu \mathrm{g} / \mathrm{ml}$; Vector Laboratories) for $2 \mathrm{hr}$. Absence of cross-reactivity between secondary antibodies was confirmed by omission of either primary antibody. All sections were observed under an Axiovert 100M microscope connected to a Zeiss laser-scanning microscope 510 (Carl Zeiss, Oberkochen, Germany).

For RCA-1 lectin histochemistry, after pretreatment with $3 \% \mathrm{H}_{2} \mathrm{O}_{2}$ and $0.1 \%$ bovine serum albumin, deparaffinized sections were incubated with biotinylated RCA-1 in PBS for 30 min. The incubation with ABC and the visualization of horseradish peroxidase activity were performed as described (Toyooka et al., 1993).

Terminal deoxynucleotidyl transferase-mediated biotinylated UTP nick end labeling (TUNEL) histochemistry combined with immunohistochemistry for pi-GST or MAP2 was performed as described (Taniike et al., 1999). In the case of MAP2 staining, pretreatment with a mouseon-mouse immunodetection kit (Vector Laboratories) was necessary.

Electron microscopy. After fixation with $3 \%$ glutaraldehyde and $1 \%$ paraformaldehyde in $0.1 \mathrm{M} \mathrm{PB}, \mathrm{pH} 7.2$, followed by postfixation with $1 \%$ osmium tetrahydroxide, coronally cut brains were routinely processed and examined. After observation of $1-\mu \mathrm{m}$-thick semithin sections stained with Toluidine blue, areas for ultrathin sections were selected and cut. Ultrathin sections of the cerebellar hemisphere were stained with uranyl acetate and lead citrate and examined with a JEM-100CX electron microscope (JEOL, Tokyo, Japan) at $80 \mathrm{kV}$.

Cell counts and statistical analysis. $\mathrm{L}-\mathrm{PGDS}^{+}$cells and $\mathrm{TUNEL}^{+}$cells were counted in paraffin sections prepared from mice at P35 and P45, six mice at each time. $\mathrm{L}-P G D S^{+}$cells were counted in 45-d-old $L-P G D S^{+/+}$ $G A L C^{t w i / t w i}$ brain parenchyma.

Statistical comparisons were made by Student's $t$ test. Values of $p<$ 0.05 were considered to be significant. 


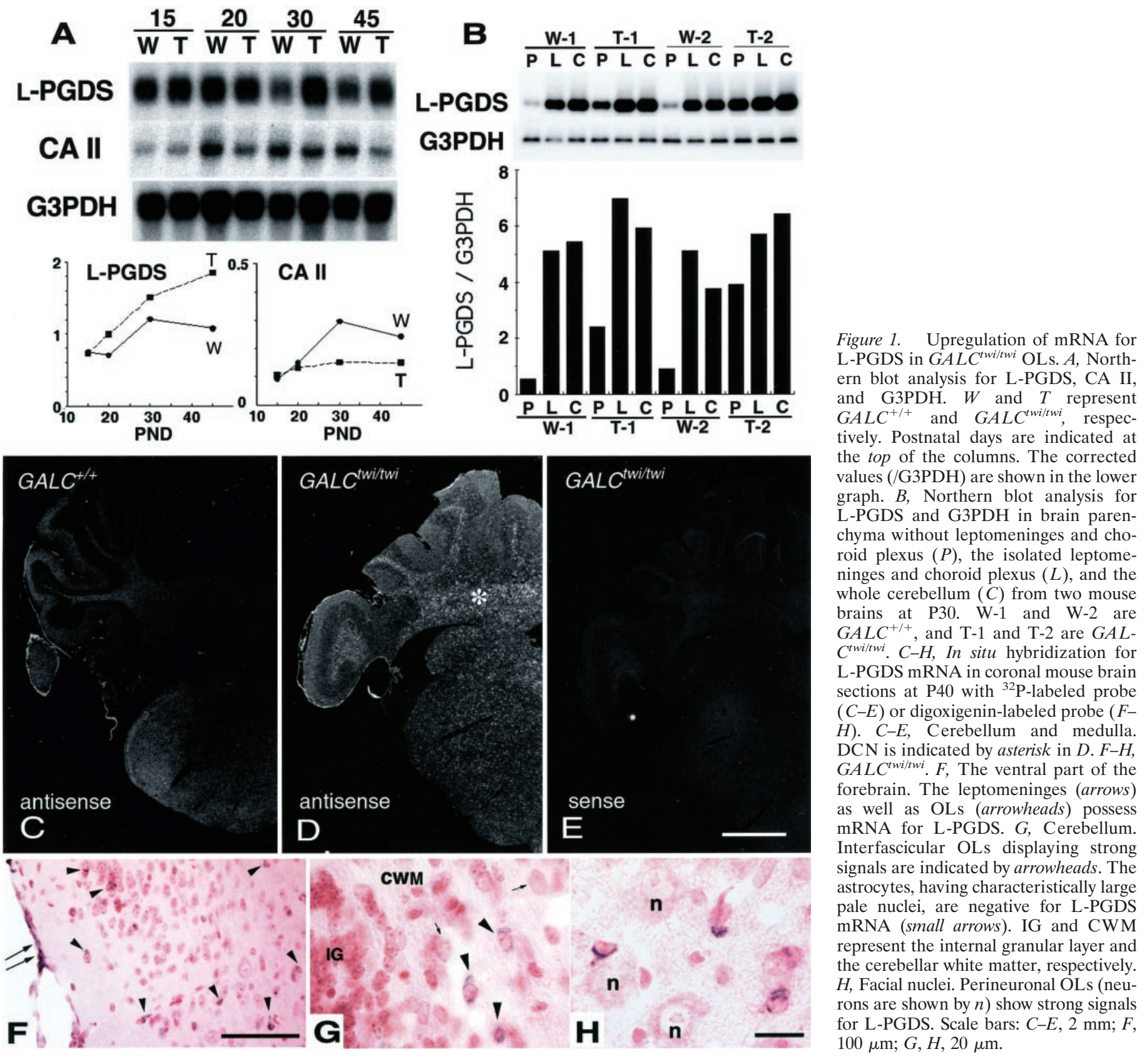

\section{RESULTS}

\section{Upregulation of L-PGDS in OLs of GALC ${ }^{\text {twi/twi }}$ mice}

Figure $1 A$ shows that L-PGDS mRNA in $G A L C^{t w i l t w i}$ brains increased progressively after $\mathrm{P} 30$ when demyelination was already obvious (Taniike and Suzuki, 1994), whereas its level in wild-type $\left(G A L C^{+/+}\right)$brains had already reached a plateau by P30. It reached a level 1.7 times higher in $G A L C^{t w i / t w i}$ than in $G A L C^{+/+}$ by $\mathrm{P} 45$. In contrast, mRNA for CA II, which is a myelin/OLassociated protein, did not increase after P20 in $G A L C^{\text {twiltwi }}$ brains and was $61 \%$ of the $G A L C^{+/+}$level at P45. L-PGDS activities in mouse brains at $\mathrm{P} 39$ were as follows (mean $\pm \mathrm{SE}$, $n=4)$ : $G A L C^{+/+}$cerebrum, $0.27 \pm 0.05 \mathrm{nmol} \cdot \mathrm{min}^{-1} \cdot \mathrm{mg}^{-1}$ protein; $G A L C^{\text {twiltwi }}$ cerebrum, $0.72 \pm 0.06 \mathrm{nmol} \cdot \mathrm{min}^{-1} \cdot \mathrm{mg}^{-1}$ protein; $G A L C^{+/+}$cerebellum, $0.28 \pm 0.04 \mathrm{nmol} \cdot \min ^{-1}$. $\mathrm{mg}^{-1}$ protein; GALC $C^{t w i t t w i}$ cerebellum, $0.74 \pm 0.11 \mathrm{nmol} \cdot$ $\mathrm{min}^{-1} \cdot \mathrm{mg}^{-1}$ protein. Thus, L-PGDS activity was significantly increased in both cerebrum $(p<0.005)$ and cerebellum $(p<$ $0.01)$ in $G A L C^{t w i l t w i}$ as compared with that in $G A L C^{+/+}$.

To exclude the possibility that the increase in L-PGDS in $G A L C^{t w i / t w i}$ brains was attributable to its increased production in leptomeninges and choroid plexus, we compared the expression level of L-PGDS mRNA between brains with and without leptomeninges (Fig. 1B). The level of L-PGDS mRNA in GALC ${ }^{t w i t t w i}$ cerebral parenchyma without leptomeninges (designated as " $\mathrm{P}$ " in Fig. $1 B$ ) increased fivefold to eightfold as compared with that of $G A L C^{+/+}$mice, whereas the levels in isolated leptomeninges and choroid plexus (designated as "L" in Fig. $1 B$ ) and in whole cerebellum ("C" in Fig. 1B) increased only 10-40\% in GALC twiltwi $^{\text {. }}$ mice. The upregulation of L-PGDS mRNA in the GALC ${ }^{t w i t w i}$ brain parenchyma was also confirmed by in situ hybridization (Fig. 1C-E). Except for its presence in leptomeninges, L-PGDS mRNA was undetectable in either $G A L C^{+/+}$or $G A L C^{t w i / t w i}$ 


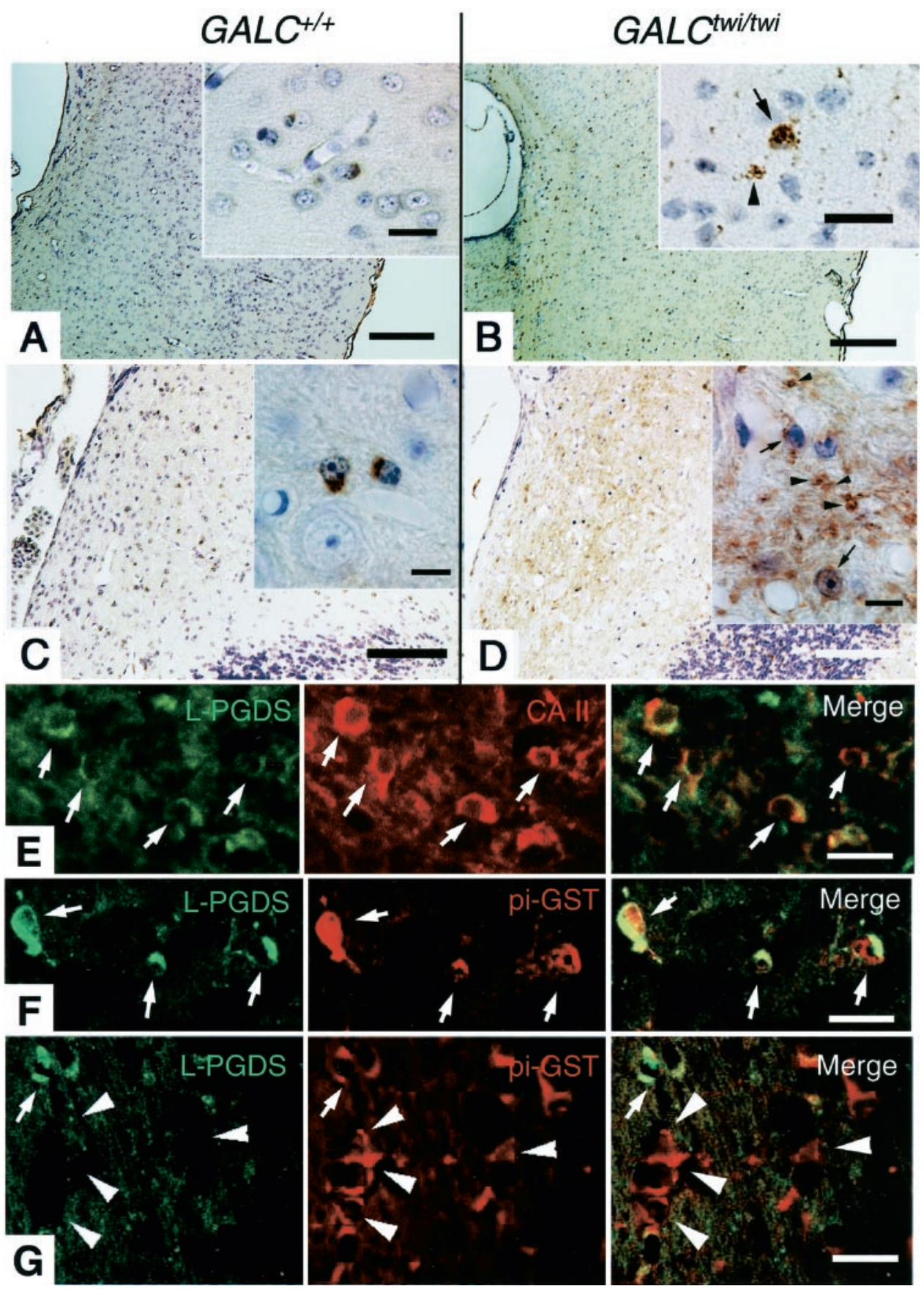

Figure 2. Increase in number of L-PGDSimmunoreactive OLs in $G A L C^{\text {twiltwi }}$ brains at $\mathrm{P} 40$. $A, B$, The primary motor area in the forebrain. Scale bars: $A, B, 200 \mu \mathrm{m}$; insets, $20 \mu \mathrm{m}$. $C, D, \mathrm{DCN}$ facing the fourth ventricle. Scale bars: $C, D, 100 \mu \mathrm{m}$; insets, $5 \mu \mathrm{m}$. Arrows and arrowheads indicate L-PGDS ${ }^{+}$ cell somas and their varicose processes, respectively, in a $G A L C^{t w i / t w i}$ brain. $E-G$, Confocal images for the double immunostaining for L-PGDS ( green) and CAII ( $E$, $r e d)$ or pi-GST $(F, G, r e d)$ of the brainstem $(E)$, cerebral cortex $(F)$, and corpus callosum $(G)$ of $G A L C^{\text {twiltwi }}$ at P40. Arrows in $E-G$ and arrowheads in $G$ indicate L-PGDS $^{+}$OLs and L-PGDS ${ }^{-}$OLs, respectively. Scale bars, $10 \mu \mathrm{m}$.

brains before the onset of demyelination at P15 (data not shown). The obvious leptomeningeal signal was recognized in both $G A L C^{+/+}$and $G A L C^{t w i / t w i}$ (Fig. $1 C, D, F$, arrows). In addition, at P40 when demyelination had already advanced, a strong signal was recognized throughout the cerebellar white matter and medulla, particularly in the deep cerebellar nuclei (DCN) (Fig. 1D, asterisk), in $G A L C^{t w i / t w i}$. Higher magnification disclosed that the intense signal was observed only in OLs in the GALC $C^{t w i / t w i}$ (Fig. $1 F-H)$. L-PGDS mRNA was recognized in both interfascicular OLs of the white matter (Fig. $1 G$ ) and perineuronal OLs of the gray matter (Fig. $1 H$ ).

In $G A L C^{+/+}$, only a few $\mathrm{L}-P G D S^{+}$perineuronal OLs were detected throughout all ages examined (Fig. $2 A, C$, insets). In contrast, in $G A L C^{t w i / t w i}$ brains, L-PGDS ${ }^{+}$OLs were increased in number in both the gray and white matter after P25, and many cells with morphological features of degenerating OLs with multiple varicose processes (Taniike et al., 1999) showed intense L-PGDS immunoreactivity at P40 (Fig. 2B,D, insets). The use of the double immunofluorescence technique showed that L-PGDS ${ }^{+}$cells were positive for neither GFAP nor S-100, markers for astrocytes, nor for F4/80, a marker for microglia/macrophages (Taniike and Suzuki, 1995; data not shown). Confocal images of $G A L C^{\text {twi/twi }}$ brains disclosed that all L-PGDS ${ }^{+}$cells were immunoreactive for CAII (Fig. $2 E$ ) or pi-GST (Fig. $2 F, G$ ) and were thus identified as OLs (Taniike et al., 1999). In addition, all perineuronal OLs were also immunoreactive for L-PGDS (Fig. $2 F$, arrows), whereas interfascicular OLs were occasionally L-PGDS $^{-}$(Fig. 2G, arrowheads). L-PGDS ${ }^{+}$OLs were abundant 


\section{L-PGDS}
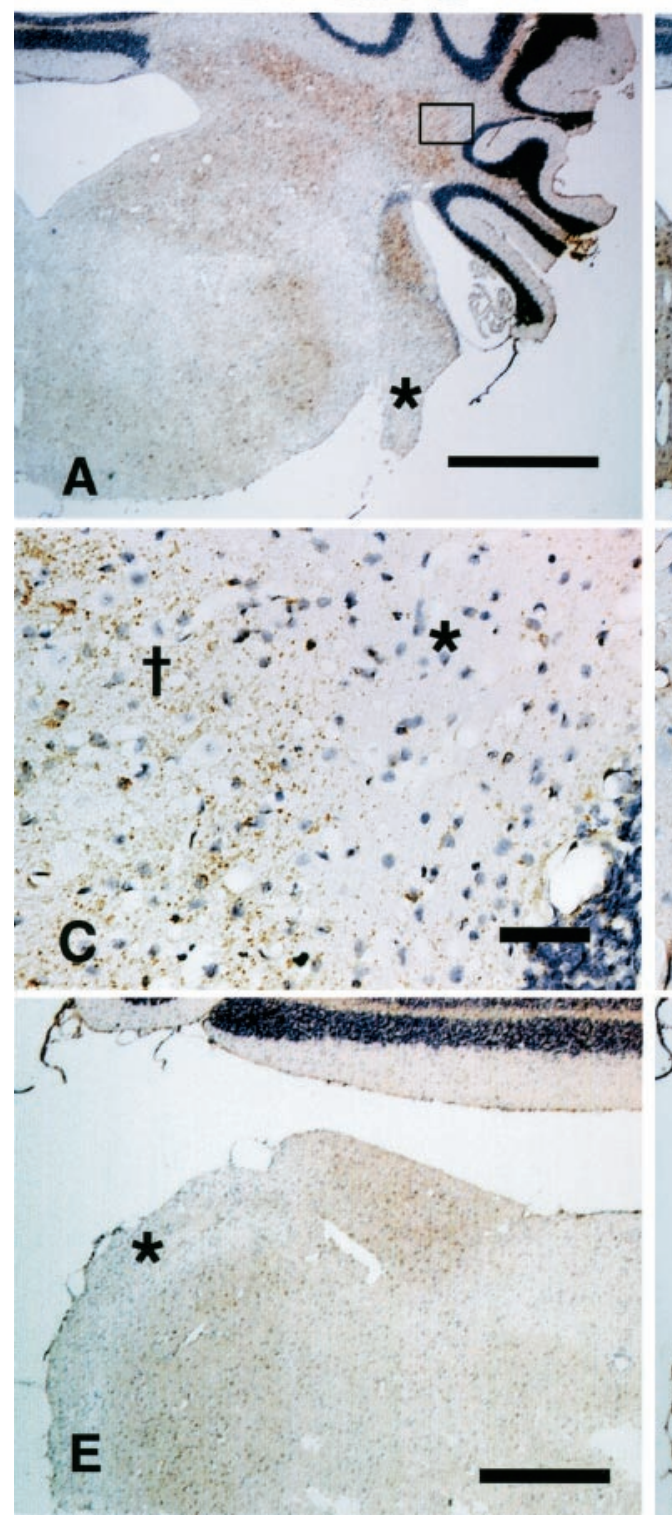

RCA-1

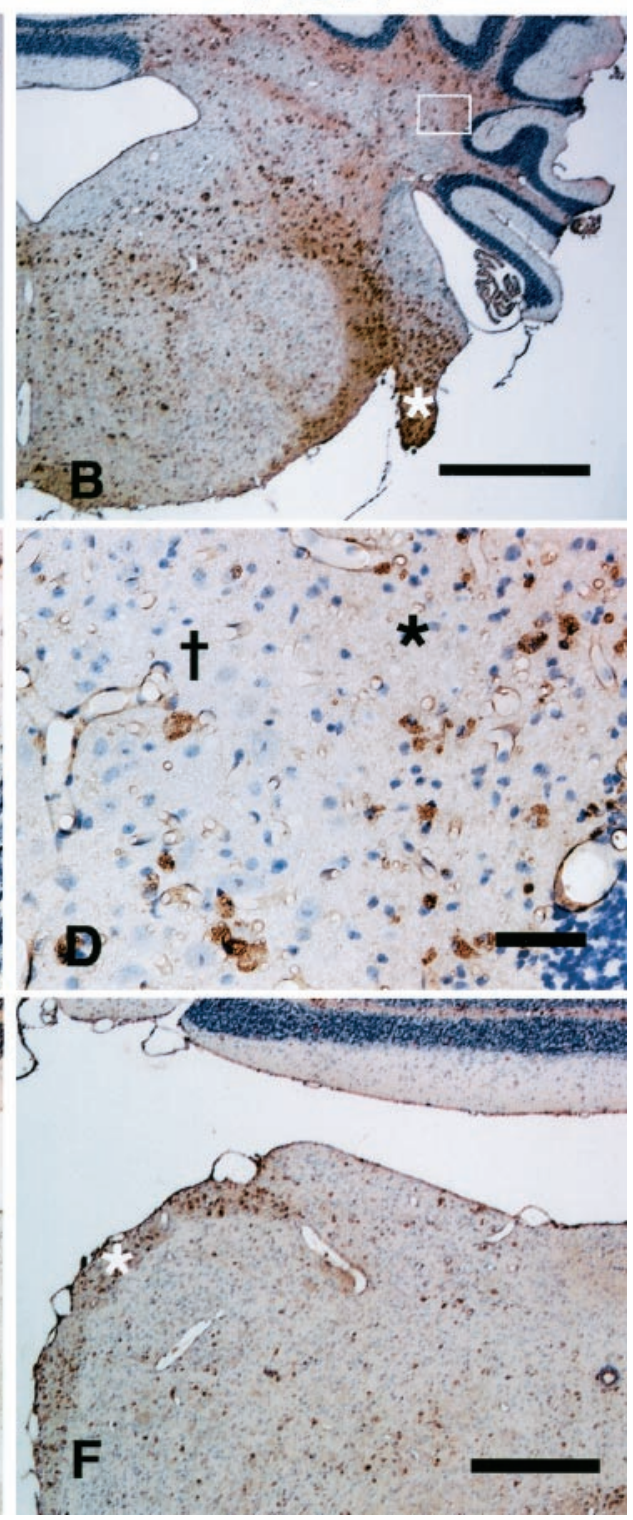

Figure 3. Inverse relationship between the distribution patterns of $\mathrm{L}-\mathrm{PGDS}^{+}$cells and microglia/macrophages in $G A L C^{t w i / t w i}$ brains at $\mathrm{P} 40 . A-D$, Cerebellopontine angle. Asterisks indicate $8 \mathrm{n}$ in $A$ and $B$. Scale bars, $1 \mathrm{~mm}$. $C$ and $D$ are higher magnification views of the boxed areas in $A$ and $B$, respectively. Asterisks and daggers indicate CWM and DCN, respectively. Scale bars, $50 \mu \mathrm{m}$. E, F, Medulla. Asterisks indicate sp5. Scale bars, $0.5 \mathrm{~mm}$. in the DCN (Fig. 2D), cerebellar cortex, anterior commissure, and optic nerve; but they were rare in the corpus callosum (Fig. $2 G$, arrows) and internal capsule, and L-PGDS was not detected at any age examined in interfascicular OLs of the intermedullary portion of the eighth nerve root $(8 \mathrm{n})$ and spinal trigeminal tract (sp5) (Fig. 3A,E), which are sites of extensive demyelination in GALC $C^{t w i / t w i}$ (Taniike and Suzuki, 1994).

These results clearly show that L-PGDS was upregulated in $G A L C^{t w i / t w i}$ OLs in a region-specific manner.

\section{Inverse relationship between the distribution of L- $\mathrm{PGDS}^{+}$OLs and the severity of demyelination in GALC ${ }^{\text {twi/twi }}$ brains}

Next we investigated the relationship between L-PGDS immunoreactivity and the severity of demyelination in $G A L C^{t w i / t w i}$ brains. Figure 3 shows serial sections of the cerebellopontine angle region (Fig. $3 A-D$ ) and the medulla (Fig. $3 E, F$ ) of the GALC $C^{t w i / t w i}$ at P40. These regions were already described to be the most severely demyelinated in GALC $C^{t w i / t w i}$ brains (Taniike and Suzuki, 1994).
Accumulation of $\mathrm{RCA}-1^{+}$scavenger macrophages, a pathological hallmark of demyelination, was obvious in 8n (Fig. 3A,B, asterisks) and in sp5 (Fig. 3E,F, asterisks), in which no L-PGDS ${ }^{+} \mathrm{OLs}$ were detected (Fig. $3 A, E$ ). On the contrary, a close-up view of the interface between cerebellar white matter (CWM) (Fig. $3 C, D$, asterisks) and DCN (Fig. 3C,D, daggers) revealed that very few macrophages had infiltrated into the DCN where L-PGDS ${ }^{+} \mathrm{OLs}$ were abundant (Fig. $3 C$ ). These data clearly show that the regional distribution profiles of L-PGDS ${ }^{+}$OLs and macrophages were in inverse relationship.

\section{Apoptotic cells significantly increased in L-PGDS $^{-/-}$GALC $^{\text {twi/twi }}$ brains}

Because OL depletion and subsequent demyelination in $G A L C^{t w i / t w i}$ are attributable to apoptosis of OLs (Taniike et al., 1999), we predicted that L-PGDS may be upregulated in OLs to provide resistance against the apoptosis and subsequent demyelination in $G A L C^{t w i / t w i}$. To verify this hypothesis, we established a mouse line doubly deficient for GALC and $L-P G D S$ (Fig. 4). 

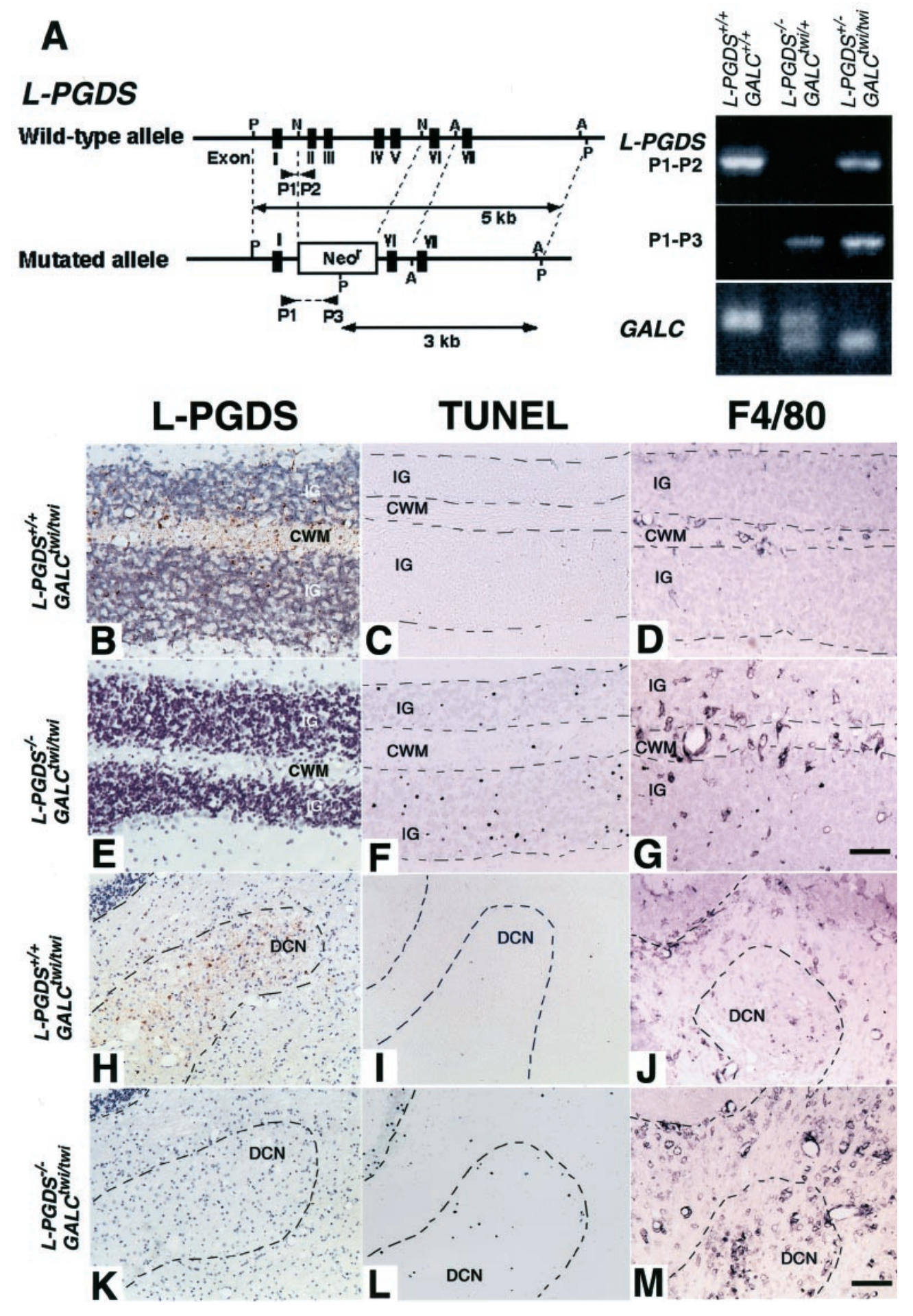

GALC
Figure 4. Enhanced apoptosis and macrophage aggregation in $L-P G D S^{-1}$ $G A L C^{t w i / t w i}$. A, The restriction map for the wild-type allele and the mutated allele for L-PGDS. Restriction sites: $P$, PvuII; N, NcoI; A, AcyI. Neo ${ }^{r}$, neomycin resistance gene. The combination of $\mathrm{P} 1 / \mathrm{P} 2$ primers or $\mathrm{P} 1 / \mathrm{P} 3$ primers was used to detect wild-type or null allele for $L-P G D S$, respectively. $G A L C$ genotype was identified by the different length of the EcoRV-digested fragments of the PCR fragments; i.e., the twitcher allele has a shorter fragment length. $B-G$, Cerebellar cortex at P45. $H-M$, DCN at P45. Scale bars, $100 \mu \mathrm{m}$.
There was no significant difference between $L-P G D S^{-/-} G A L$ $C^{t w i / t w i}$ and $L-P G D S^{+/+} G A L C^{t w i / t w i}$ in terms of the life span $\left(50.3 \pm 0.3 \mathrm{~d}\right.$ in $L-P G D S^{+/+} G A L C^{t w i / t w i}$ vs $50.1 \pm 0.6 \mathrm{~d}$ in $\left.L-P G D S^{-1-} G A L C^{t w i / t w i} ; n=9\right)$. The neuropathology of both genotypes was similar until P35. Psychosine, which is a potent neurotoxin that accumulates in the $G A L C^{t w i / t w i}$ brain as a consequence of the genetic defect, has been suggested to induce OL dysfunction and apoptosis. The content of psychosine at P45 was the same in the $L-P G D S^{-/-} G A L C^{t w i / t w i}$ (cerebrum, $6.67 \pm 1.07$ $\mathrm{ng} / \mathrm{mg}$ protein; cerebellum, $22.74 \pm 6.87 \mathrm{ng} / \mathrm{mg}$ protein) and in the $L-P G D S^{+/+} G A L C^{t w i / t w i}$ (cerebrum, $7.68 \pm 1.92 \mathrm{ng} / \mathrm{mg}$ protein; cerebellum, $22.40 \pm 6.41 \mathrm{ng} / \mathrm{mg}$ protein) brains.

However, at P45, L-PGDS $S^{-/-} G A L C^{t w i / t w i}$ brains showed more severe demyelination than the $L-P G D S^{+/+} G A L C^{t w i / t w i}$ ones. At $\mathrm{P} 35$, the number of $\mathrm{TUNEL}^{+}$nuclei was already moderately increased in the caudate-putamen and $8 \mathrm{n}$ of $L-P G D S^{-/-}$ $G A L C^{t w i / t w i}$ brains; however, by $\mathrm{P} 45$, this number was drastically increased in the $L-P G D S^{-/-} G A L C^{t w i / t w i}$ brains (Fig. $4 F, L$ ) as compared with the number in the $L-P G D S^{+/+} G A L C^{\text {twi/twi }}$ ones (Fig. 4C,I). In $L-P G D S^{-/-} G A L C^{t w i / t w i}$ brains, TUNEL ${ }^{+}$cells 

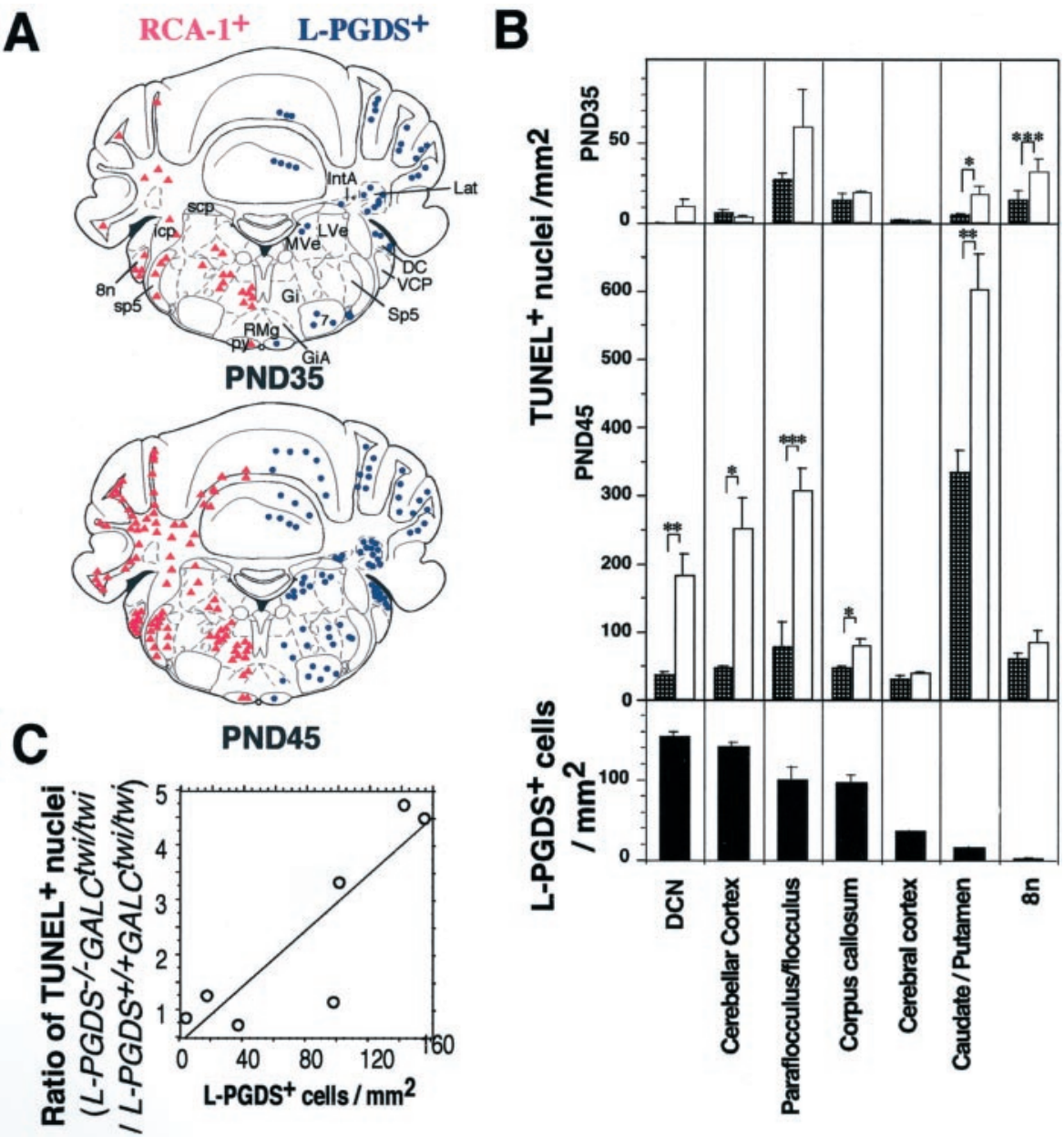

Figure 5. Positive relationship between the regional distribution of $\mathrm{L}^{-\mathrm{PGDS}^{+}} \mathrm{OLs}^{+}$and the increase in apoptotic cells caused by L-PGDS deficiency. $A$, The population of RCA- $1^{+}$microglia/macrophages ( pink triangles in the left half) and L-PGDS ${ }^{+}$cells (blue dots in the right half) in $L-P G D S^{+/+} G A L C^{t w i / t w i}$ brains at P35 and P45. Abbreviations: 7, facial nucleus; $8 n$, vestibulocochlear nerve root; $D C$, dorsal cochlear nucleus; $G i$, gigantocellular reticular nucleus; $G i A$, gigantocellular reticular nucleus ( $\alpha$ part); Int $A$, interposed cerebellar nucleus (anterior part); icp, inferior cerebellar peduncle; $L a t$, lateral cerebellar nucleus; $L v e$, lateral vestibular nucleus; $M v e$, medial vestibular nucleus; $p y$, pyramidal tract; $R M g$, raphe magnus nucleus; $s c p$, superior cerebellar peduncle; $s p 5$, spinal trigeminal tract; $S p 5$, spinal trigeminal nucleus; $V C P$, ventral cochlear nucleus (posterior part). B, The population of TUNEL $^{+}$apoptotic nuclei (P35 and P45; hatched columns, L-PGDS ${ }^{+/+} G A L C^{\text {twiltwi; }}$ open columns, $\left.L-P G D S^{-/-} G A L C^{t w i / t w i}\right)$ and L-PGDS ${ }^{+}$cells of $L-P G D S^{+/+} G A L C^{t w i / t w i}$ at $\mathrm{P} 45$ (solid columns) in seven regions. ${ }^{*} p<0.05 ;{ }^{* *} p<0.01 ;{ }^{* * *} p<$ 0.005. $C$, The ratio of the number of TUNEL ${ }^{+}$ cells in $L-P G D S^{-1-} G A L C^{t w i / t w i}$ versus that in $L-P G D S^{+/+} G A L C^{t w i / t w i}$ at $\mathrm{P} 45$ was plotted against the population of $\mathrm{L}-\mathrm{PGDS}^{+}$cells in $L-P G D S^{+/+} G A L C^{t w i / t w i}$ brains. $r=0.875(p<$ $0.01)$. were especially increased in number in the gray matter such as the internal granular layer of the cerebellum (Fig. 4C,F, compare IG) or DCN (Fig. 4, compare $I, L$ ). The number of apoptotic nuclei was also increased in the white matter such as CWM (Fig. 4, compare $C, F$ ) and corpus callosum. In both the DCN and IG of $L-P G D S^{+/+} G A L C^{\text {twi/twi }}$ brains, a large number of $\mathrm{L}-P G D S^{+}$ perineuronal OLs was observed (Fig. 4B,H). In $L-P G D S^{-1-}$ $G A L C^{t w i / t w i}$ brains, however, apoptotic cell death was accompanied by many $\mathrm{F} 4 / 80^{+}$activated microglia and/or infiltrating macrophages in the IG (Fig. $4 G$ ) and DCN (Fig. 4M), where F4/80+ cells were quite few (Fig. 4D,J) with very mild demyelination, as previously described (Fig. 3, daggers), in the $L-P G D S^{+/+}$ $G A L C^{\text {twi/twi }}$ brains.

Figure $5 A$ summarizes the spatiotemporal distributional change in $\mathrm{RCA}-1^{+}$microglia/macrophages, a pathological hallmark of demyelination (Taniike et al., 1994), and L-PGDS ${ }^{+}$OLs in the $L-P G D S^{+/+} G A L C^{t w i / t w i}$ brains. In the most severely affected areas such as the $8 \mathrm{n}$ or $\mathrm{sp} 5$, very few L-PGDS ${ }^{+}$OLs were observed throughout the ages examined. On the other hand, in the least affected areas such as the lateral cerebellar nucleus (Fig. $5 A$, Lat) and dorsal cochlear nucleus (Fig. 5A, DC), L-PGDS ${ }^{+}$ cells were found in abundance from the early stage of demyelination. Figure $5 B$ summarizes the population of L-PGDS ${ }^{+}$OLs and apoptotic nuclei counted in seven brain regions. Because perineuronal OLs tended to express more intense L-PGDS immunoreactivity than interfascicular OLs as described above, we chose to analyze four regions from gray matter (cerebral cortex, caudate-putamen, cerebellar cortex of anterior vermis, and DCN) and two regions from white matter (corpus callosum and $8 n$ ). In addition, because the increase in number of TUNEL ${ }^{+}$ nuclei was the most remarkable in the paraflocculus/flocculus of cerebellum, the gray and white matter of this region was analyzed as a whole. Whereas TUNEL ${ }^{+}$nuclei density (nuclei $/ \mathrm{mm}^{2}$ ) was already significantly increased at P35 (Fig. 5B, top panel) in the caudate-putamen (from $5.6 \pm 0.5$ in $L-P G D S^{+/+} G A L C^{\text {twi/twi }}$ to $18.3 \pm 5.0$ in $L-P G D S^{-1-} G A L C^{t w i / t w i} ; p<0.05$ ), and $8 \mathrm{n}$ (from $14.4 \pm 6.1$ to $32.1 \pm 7.7 ; p<0.005)$, it was remarkably increased at $\mathrm{P} 45$ (Fig. 5B, middle panel) in the DCN (from $36 \pm 5$ in $L-P G D S^{+/+} G A L C^{t w i / t w i}$ to $183 \pm 32$ in $L-P G D S^{-/-} G A L C^{t w i / t w i}$; $p<0.01$ ), cerebellar cortex (from $47 \pm 3$ to $251 \pm 32 ; p<0.05$ ), paraflocculus/flocculus (from $79 \pm 36$ to $307 \pm 34 ; p<0.005$ ), caudate-putamen (from $333 \pm 34$ to $603 \pm 54 ; p<0.01$ ), and corpus callosum (from $47 \pm 3$ to $80 \pm 10 ; p<0.05$ ). No significant difference in the number of $\mathrm{TUNEL}^{+}$nuclei was observed in the cerebral cortex $(31 \pm 5$ and $40 \pm 2)$ and $8 \mathrm{n}(60 \pm 9$ and $86 \pm 17)$ between the respective $L-P G D S^{+/+} G A L C^{t w i / t w i}$ and $L-P G D S^{-/-}$ $G A L C^{t w i / t w i}$ brains at P45. The density of L-PGDS ${ }^{+}$OLs (in cells per square millimeter) in 45-d-old $P G D S^{+/+} G A L C^{\text {twi/twi }}$ brains (Fig. 5B, bottom panel) was high in $\mathrm{DCN}(153.4 \pm 6.2)$ and cerebellar cortex $(140.9 \pm 6.3)$, moderate in the paraflocculus/ flocculus (99.4 \pm 16.7$)$ and corpus callosum (95.8 \pm 10.2$)$, and low in the cerebral cortex $(35.3 \pm 1.3)$, caudate-putamen $(15.0 \pm 1.5)$, and $8 \mathrm{n}(1.8 \pm 1.8)$. When the ratio of apoptotic nuclei in $L-P G D S^{-/-} G A L C^{t w i / t w i}$ versus those in $L-P G D S^{+/+} G A L C^{t w i / t w i}$ 
L-PGDS+/+GALCtwi/twi
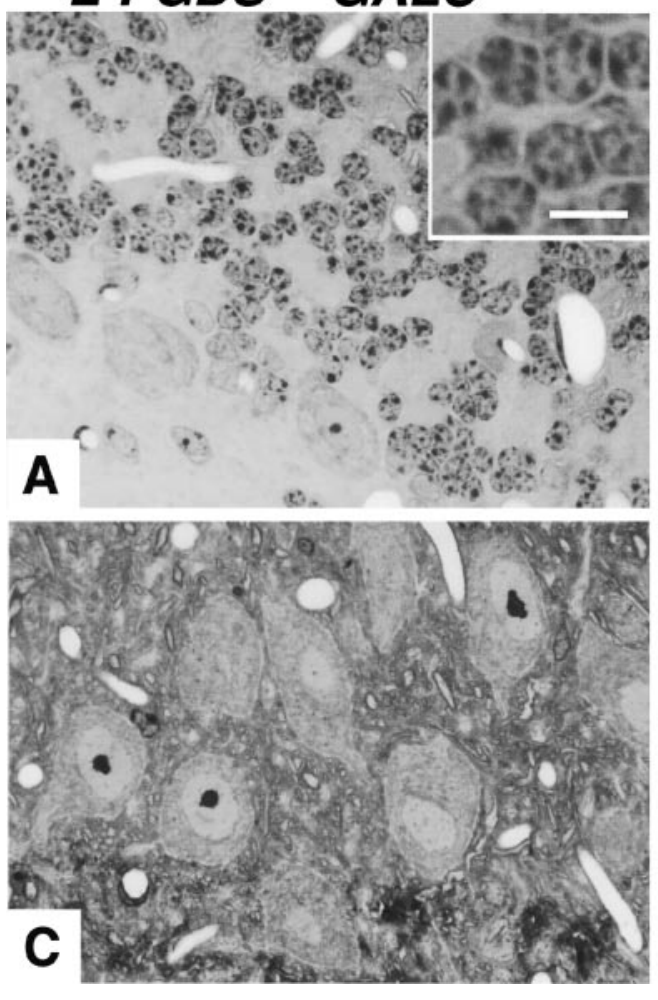

L-PGDS ${ }^{-/-G A L C} C^{t w i / t w i}$
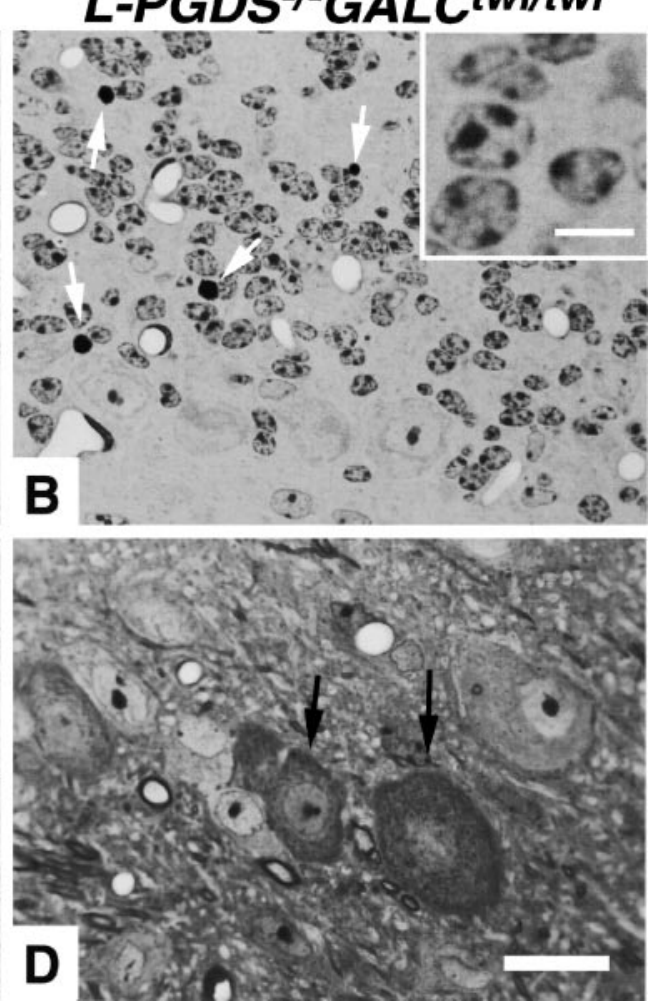

Figure 6. Degeneration and enhanced apoptosis of cerebellar neurons in $L-P G D S^{-/-} G A L C^{t w i / t w i}$ brains at $\mathrm{P} 45$ Semithin sections $(1 \mu \mathrm{m})$ stained with Toluidine blue. $A, B$, The Purkinje cells and IG. Apoptotic nuclei are indicated by white arrows. $C, D, \mathrm{DCN}$ neurons. Dark degenerating neurons are indicated by arrows in $D$. Scale bars: $15 \mu \mathrm{m}$; insets, $5 \mu \mathrm{m}$.

was plotted against the population of $\mathrm{L}_{-\mathrm{PGDS}}{ }^{+} \mathrm{OLs}$ in the $L-P G D S^{+/+} G A L C^{t w i / t w i}$ (Fig. 5C), a linear positive correlation between these two parameters was observed, suggesting a dosedependent effect of L-PGDS against apoptosis. In addition, the finding that apoptotic nuclei were more increased in number in the gray matter (DCN, cerebellar cortex, caudate-putamen) than in the white matter (corpus callosum and 8n) implies not only a larger anti-apoptotic effect by perineuronal OLs than by interfascicular OLs but also the possibility of neuronal apoptosis in $L-P G D S^{-/-} G A L C^{t w i / t w i}$ brains.

\section{Neuronal apoptosis is induced in L-PGDS $^{-/-}$GALC $^{\text {twi/twi }}$}

We chose the cerebellum for further analysis, because a large number of $\mathrm{TUNEL}^{+}$nuclei were recognized there. The observation of $1 \mu \mathrm{m}$ cerebellar sections disclosed many apoptotic nuclei (Fig. 6B, white arrows) and the loss of granular cells in the $L-P G D S^{-1-} G A L C^{t w i / t w i}$. Granular cells were present in a cluster or a row in $L-P G D S^{+/+} G A L C^{t w i / t w i}$ (Fig. 6A), whereas these cells were often solitary in $L-P G D S^{-1-} G A L C^{t w i / t w i}$ (Fig. 6B). In addition, the nuclear size of granular cells was much more variable and usually smaller in $L-P G D S^{-/-} G A L C^{t w i / t w i}$ than in $L-P G D S^{+/+}$ $G A L C^{t w i / t w i}$. The chromatin of $L-P G D S^{-/-} G A L C^{t w i / t w i}$ granular cells was condensed into fewer and larger nucleoli than that of $L-P G D S^{+/+} G A L C^{t w i / t w i}$ ones, making these nuclei lighter and clearer (Fig. $6 A, B$, insets). These nuclear changes are suggestive of the early phase of apoptosis. In the DCN, degenerating neurons with a dark cytoplasm were frequently observed in $L-P G D S^{-1-} G A L C^{t w i / t w i}$ brains (Fig. $6 D$, arrows) but not at all in $L-P G D S^{+/+} G A L C^{t w i / t w i}$ ones (Fig. $6 C$ ).
In the IG of $L-P G D S^{-1-} G A L C^{t w i / t w i}$, most of the TUNEL ${ }^{+}$ cells were pi-GST ${ }^{-}$(Fig. 7A) and $\mathrm{MAP}^{+}$neurons (Fig. 7B), whereas a considerable number of TUNEL ${ }^{+}$cells in the $\mathrm{CWM}$ and molecular layer (ML) (Fig. 7A, arrows) were identified as pi-GST ${ }^{+}$OLs. We observed no $\mathrm{TUNEL}^{+}$cells in $L-P G D S^{-/-}$ $G A L C^{+/+}$and no $\mathrm{MAP}^{+} \mathrm{TUNEL}^{+}$cells in $L-P G D S^{+/+}$ $G A L C^{t w i / t w i}$ (data not shown).

Electron microscopic investigation disclosed that many cells in the IG of $L-P G D S^{-/-}$GALC $^{t w i / t w i}$ brains showed nuclear changes characteristic of apoptosis such as ruffled nucleoli or condensed and clumpy chromatin beneath their nuclear membrane (Fig. $7 C, E)$. Some of these apoptotic cells showed synaptic contact (Fig. 7D, arrowheads), indicating them to be cerebellar granular cells. A tubulovesicular structure was frequently visible in axons in $L-P G D S^{-/-}$GALC $^{t w i / t w i}$ (Fig. $7 F$, asterisk). These structures have been reported to be present in cerebellum under diverse experimental and pathological conditions, and they may represent a stage in the degeneration of axonal collaterals and terminals (for review, see Sotelo and Palay, 1971). Axons with these structures were also recognized in the $L-P G D S^{+/+} G A L C^{t w i / t w i}$ cerebellum $(7.3 \pm 4.7 / 100$ myelinated axons $)$, but were significantly increased in number in $L-P G D S^{-/-}$GALC $^{t w i / t w i}(33.4 \pm 3.6 / 100$ myelinated axons; $p<0.02$ ), suggesting that axonal integrity was perturbed in the L-PGDS $S^{-1-}$ GALC $^{\text {twiltwi }}$ because of the loss of axonal contact with apoptotic neurons.

From these lines of evidence, we concluded that the augmentation of apoptosis in $L-P G D S^{-/-} G A L C^{t w i / t w i}$ was caused by disappearance of the anti-apoptotic function of L-PGDS. L-PGDS produced by perineuronal OLs thus appears to play a protective role against neuronal degeneration. 


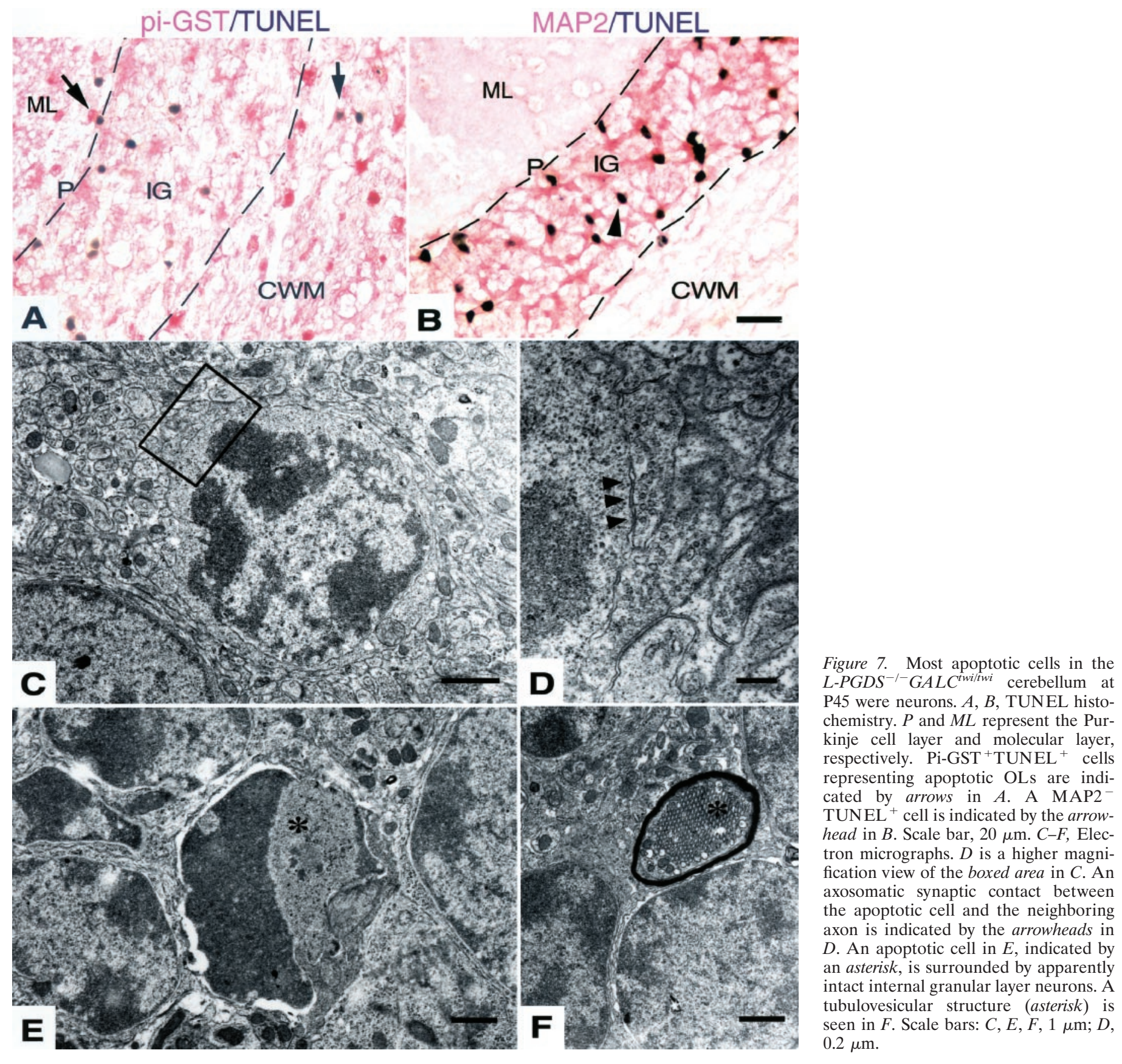

\section{DISCUSSION}

\section{L-PGDS as the first OL-associated protein upregulated during demyelination}

In this report, we demonstrate that L-PGDS expression is upregulated in $G A L C^{t w i / t w i}$ OLs with progressive demyelination (Figs. 1, 2). As noted in other models of demyelination, such as experimental autoimmune encephalomyelitis (Itoyama and Webster, 1982; Yao et al., 1995), virus-induced demyelination (Rodriguez et al., 1994; Barac-Latas et al., 1997), and cuprizone intoxication (Fujita et al., 1990; Tansey et al., 1996; Morell et al., 1998), the expression of myelin/OL-associated proteins, such as CA II (Fig. 1A), myelin basic protein, myelin-associated glycoprotein, proteolipid protein, and UDP-galactose:ceramide galactosyltransferase was downregulated after the commencement of demyelination in $G A L C^{t w i / t w i}$ (Taniike et al., 1998). The expression of pi-GST, another OL-associated protein, remained constant during demyelination in $G A L C^{t w i / t w i}$ (Taniike et al., 1999). Besides the possible upregulation of apoptosis-associated proteins such as caspases, L-PGDS is the first non-apoptosis-associated protein demonstrated to be upregulated in OLs during progressive demyelination. In a recent report, L-PGDS was the second most abundant gene upregulated in the brains of patients with multiple sclerosis (Chabas et al., 2001). Moreover, our preliminary data strongly suggested that L-PGDS was upregulated in active lesions in mice with experimental autoimmune encephalomyelitis (data not shown). These findings suggested that the upregulation of L-PGDS was a common phenomenon among the demyelinating diseases, regardless of their primary etiology.

Because of the inverse correlation between L-PGDS ${ }^{+}$OLs and the severity of demyelination in $G A L C^{t w i / t w i}$ brains (Fig. 3), 
we hypothesized an anti-apoptotic function of upregulated L-PGDS in the CNS. However, the evaluation was made complex by the presence of a considerable number of hematogeneous cells, which infiltrate into $G A L C^{t w i / t w i}$ brains after P30 (Wu et al., 2000) and secrete apoptotic cytokines such as TNF- $\alpha$ in $G A L C^{t w i / t w i}$ white matter (K. Shimono, Y. Fujitani, I. Mohri, M. Taniike, and Y. Urade, unpublished observations). The reason why the number of $\mathrm{L}-P G D S^{+}$cells was not simply inversely related to the number of apoptotic nuclei in either $L-P G D S^{-/-} G A L C^{t w i / t w i}$ or $L-P G D S^{+/+} G A L C^{t w i / t w i}$ brains might be explained by the presence of a significant number of apoptotic macrophages as well as apoptotic effects of TNF- $\alpha$.

For example, in the caudate-putamen or the white matter of the paraflocculus/flocculus, where TNF- $\alpha$ expression was high with a lot of infiltrating macrophages, the number of TUNEL ${ }^{+}$ nuclei was unproportionally high. Even in these regions, the anti-apoptotic effect of L-PGDS was obvious, and the TUNEL ${ }^{+}$ nuclei increased in $L-P G D S^{-/-} G A L C^{t w i / t w i}$. On the other hand, in the regions with minimal cellular infiltration such as DCN or cerebellar cortex, $\mathrm{TUNEL}^{+}$nuclei increased multi-fold in $L-P G D S^{-1-} G A L C^{t w i / t w i}$ when compared with their number in $L-P G D S^{+/+} G A L C^{t w i / t w i}$.

The distribution of $\mathrm{L}_{-} \mathrm{PGDS}^{+}$OLs was region specific. $\mathrm{TUNEL}^{+}$nuclei-rich areas in $L-P G D S^{+/+} \mathrm{GALC}^{\text {twi/twi }}$ brains at P45 such as $8 \mathrm{n}$ or caudate-putamen contained only a small number of $\mathrm{L}-P G D S^{+}$cells, and vice versa for $\mathrm{TUNEL}^{+}$nucleipoor areas such as the VCA or DCN (Fig. 5A,B). As compared with the number in $L-P G D S^{+/+} G A L C^{\text {twi/twi }}$, the number of apoptotic cells in $L-P G D S^{-1-} G A L C^{t w i / t w i}$ increased in 35-d-old as well as 45-d-old mice (Figs. 4, 5B,C). From these lines of evidence, we verified the anti-apoptotic function of upregulated L-PGDS in the CNS. In 8 n or caudate-putamen of $L-P G D S^{+/+}$ $G A L C^{t w i / t w i}$ brains, the number of L-PGDS ${ }^{+}$OLs was constantly small, whereas the number of apoptotic OLs recognized as TUNEL $^{+}$pi-GST $^{+}$cells (Taniike et al., 1999) remarkably increased in an age-dependent manner. Thus, we concluded that the upregulation of L-PGDS does not simply reflect an ongoing apoptosis in OL but possibly reflects heterogeneity of OL subpopulations with regard to L-PGDS inducibility.

The dysfunction of Schwann cells leading to peripheral demyelination is the principal cause of death in $G A L C^{t w i / t w i}$ mice (Taniike et al., 1994). L-PGDS was neither expressed in Schwann cells of $G A L C^{+/+}$nor induced in those of $G A L C^{t w i / t w i}$, and there was no significant difference in the life span between the $L-P G D S^{+/+} G A L C^{t w i / t w i}$ and $L-P G D S^{-/-} G A L C^{t w i / t w i}$ mice.

\section{Possible anti-apoptotic mechanisms of L-PGDS}

Because L-PGDS is a bifunctional protein acting as a $\mathrm{PGD}_{2^{-}}$ producing enzyme and as a lipophilic ligand-carrier protein of the lipocalin family (Urade and Hayaishi, 2000a), there are at least two possibilities for its anti-apoptotic mechanism, as discussed below.

$\mathrm{PGD}_{2}$ elicits its biological actions through binding to the $\mathrm{G}_{\mathrm{s}^{-}}$ coupled D-type PG receptor (DPR; Mizoguchi et al., 2001) or to the G $\alpha$ i-coupled CRTH2 receptor (Hirai et al., 2001). Otherwise, $\mathrm{PGD}_{2}$ is dehydrated to yield the $\mathrm{J}$ series of PGs such as 15-deoxy$\Delta^{12,14}-\mathrm{PGJ}_{2}$ in vitro, which has been identified as a ligand for peroxisome proliferator-activated receptor- $\gamma$ (PPAR- $\gamma$; Forman et al., 1995; Kliewer et al., 1995). PGD 2 increases intracellular cAMP through its binding to DPR (Hirata et al., 1994). The increased cAMP prevents oligodendroglial excitotoxicity and the eventual death of these cells (Yoshioka et al., 1998). Thus, $\mathrm{PGD}_{2}$ produced by upregulated L-PGDS in perineuronal OLs may protect these cells from apoptosis by an increase in intracellular cAMP levels mediated via DPR. CRTH2 is expressed in the mouse brain (Abe et al., 1999), but its function and cellular localization are still unknown. Although the natural occurrence of 15 -deoxy- $\Delta^{12,14}-\mathrm{PGJ}_{2}$ in the brain remains to be clarified, activation of PPAR- $\gamma$ induces apoptosis in several cell lines (Kawahito et al., 2000; Padilla et al., 2000; Rohn et al., 2001). It is, therefore, worth studying the contribution of CRTH2 and PPAR $\gamma$ pathways to the apoptosis of OLs in $G A L C^{t w i / t w i}$.

On the other hand, $\mathrm{PGD}_{2}$ inhibits the expression of inducible nitric oxide synthase (iNOS) in vascular smooth muscle cells (Nagoshi et al., 1998). iNOS induces demyelination and/or OL apoptosis (Gilg et al., 2000; Liu et al., 2001; Molina-Holgado et al., 2001) and apoptosis of cerebellar granular neurons (MincGolomb et al., 1994, 1996; Sato et al., 1996). Many cerebellar granular neurons showed apoptotic changes in $L-P G D S^{-/-}$ $G A L C^{t w i / t w i}$ (Figs. 4, 6, 7); however, the upregulation of iNOS in $L-P G D S^{-/-} G A L C^{t w i / t w i}$ was not clearly recognized (data not shown). Therefore, we do not consider iNOS to play a major role in the neuronal apoptosis in $G A L C^{t w i / t w i}$ brains.

As a lipocalin, L-PGDS is secreted into the CSF and binds to and transports small hydrophobic molecules such as biliverdin, bilirubin, and retinoic acid (for review, see Urade and Hayaishi, 2000a). Therefore, L-PGDS may work as a scavenger of gliotoxic and neurotoxic molecules to protect OLs and neurons from degeneration. Psychosine is also a small hydrophobic molecule and a potent neurotoxin that accumulates in $G A L C^{t w i / t w i}$ (Igisu and Suzuki, 1984a,b); however, only weak affinity between L-PGDS and psychosine was detected by surface plasmon resonance spectroscopy (data not shown). In addition, psychosine levels of $L-P G D S^{+/+} G A L C^{t w i / t w i}$ and $L-P G D S^{-/-} G A L C^{t w i / t w i}$ brains were not significantly different, as described in Results. It is, therefore, unlikely that L-PGDS is involved in scavenging psychosine.

It was recently reported that L-PGDS induced apoptosis in PC-12 cells (Ragolia et al., 2001) or pig kidney LLC-PK1 cells (Maesaka et al., 2001). Moreover, the 24p3 protein, which is another lipocalin evolutionally closely related to L-PGDS (Toh et al., 1996), was reported to induce apoptosis of IL-3-deprived hematopoietic cells (Devireddy et al., 2001). These lines of evidence strongly suggested that L-PGDS may function as an apoptotic or anti-apoptotic molecule depending on its concentration, cell types, and so on. It is also possible that infiltrating macrophages produced PGs at a level high enough to induce apoptosis, but that in the areas with little cellular infiltration, the moderate amount of $\mathrm{PGD}_{2}$ released by OLs is served an anti-apoptotic role. The anti-apoptotic mechanism of L-PGDS in GALC $C^{\text {twittwi }}$ will be clarified by a gene transfer experiment in which either the intact L-PGDS or mutated L-PGDS gene, the latter encoding the protein that has lost enzymatic activity and functions only as a lipocalin, is injected to $L-P G D S^{-1-} G A L C^{t w i / t w i}$ brains to see by which construct the augmented apoptosis is restored to the $L-P G D S^{+/+} G A L C^{t w i / t w i}$ level.

\section{Novel OL-neuronal interaction mediated by L-PGDS}

As evident from our previous report that showed L-PGDS immunoreactivity in 8-week-old rat brains and not in 2-week-old ones in active myelination (Urade et al., 1987), the function of L-PGDS in OLs is unlikely to be linked to myelination but to cellular maintenance. It is also noteworthy that the L-PGDS immunoreactivity of perineuronal OLs in the gray matter was 
more intense than that of interfascicular myelinating OLs in the white matter of 40-d-old $L-P G D S^{+/+} G A L C^{t w i / t w i}$ mice (Fig. 2). Only a few reports have proposed functions of perineuronal OLs: Ludwin $(1979,1984)$ found that perineuronal OLs in the periventricular gray remyelinated axons in cuprizone-induced or traumainduced demyelination and concluded that these OLs functioned similarly as myelinating OLs. D'Amelio et al. (1990) demonstrated that immunoreactivity for glutamine synthetase was distributed in perineuronal OLs as well as in astrocytes and that perineuronal OLs fulfill a functional role more akin to that of astrocytes. We propose here a novel function of perineuronal OLs, i.e., protection of neurons from apoptosis by upregulation of L-PGDS, which was most dramatically demonstrated in granular cell neurons. This is a novel example of OL-neuronal interaction.

The results of this study not only cast a new light on the function of perineuronal OLs but also have potentially important implications for the treatment of neurodegenerative diseases as well as the demyelinating disorders.

\section{REFERENCES}

Abe H, Takeshita T, Nagata K, Arita T, Endo Y, Fujita T, Takayama H, Kubo M, Sugamura K (1999) Molecular cloning, chromosome mapping and characterization of the mouse CRTH2 gene, a putative member of the leukocyte chemoattractant receptor family. Gene 227:71-77.

Barac-Latas V, Suchanek G, Breitschopf H, Stuehler A, Wege H, Lassmann H (1997) Patterns of oligodendrocyte pathology in coronavirusinduced subacute demyelinating encephalomyelitis in the Lewis rat. Glia 19:1-12.

Beuckmann CT, Lazarus M, Gerashchenko D, Mizoguchi A, Nomura S, Mohri I, Uesugi A, Kaneko T, Mizuno N, Hayaishi O, Urade Y (2000) Cellular localization of lipocalin-type prostaglandin D synthase (betatrace) in the central nervous system of the adult rat. J Comp Neurol 428:62-78.

Blodorn B, Mader M, Urade Y, Hayaishi O, Felgenhauer K, Bruck W (1996) Choroid plexus: the major site of mRNA expression for the beta-trace protein (prostaglandin D synthase) in human brain. Neurosci Lett 209:117-120.

Chabas D, Baranzini SE, Mitchell D, Bernard CC, Rittling SR, Denhardt DT, Sobel RA, Lock C, Karpuj M, Pedotti R, Heller R, Oksenberg JR, Steinman L (2001) The influence of the proinflammatory cytokine, osteopontin, on autoimmune demyelinating disease. Science 294:1731-1735.

Chomczynski P, Sacchi N (1987) Single-step method of RNA isolation by acid guanidinium thiocyanate-phenol-chloroform extraction. Anal Biochem 162:156-159.

D'Amelio F, Eng LF, Gibbs MA (1990) Glutamine synthetase immunoreactivity is present in oligodendroglia of various regions of the central nervous system. Glia 3:335-341.

Devireddy LR, Teodoro JG, Richard FA, Green MR (2001) Induction of apoptosis by a secreted lipocalin that is transcriptionally regulated by IL-3 deprivation. Science 293:829-834.

Duchen LW, Eicher EM, Jacobs JM, Scaravilli F, Teixeira F (1980) Hereditary leucodystrophy in the mouse: the new mutant twitcher. Brain 103:695-710.

Eguchi N, Minami T, Shirafuji N, Kanaoka Y, Tanaka T, Nagata A, Yoshida N, Urade Y, Ito S, Hayaishi O (1999) Lack of tactile pain (allodynia) in lipocalin-type prostaglandin D synthase-deficient mice. Proc Natl Acad Sci USA 96:726-730.

Forman BM, Tontonoz P, Chen J, Brun RP, Spiegelman BM, Evans RM (1995) 15-Deoxy- $\Delta^{12,14}$-prostaglandin $\mathbf{J}_{2}$ is a ligand for the adipocyte determination factor PPAR $\gamma$. Cell 83:803-812.

Fujita N, Ishiguro H, Sato S, Kurihara T, Kuwano R, Sakimura K, Takahashi Y, Miyatake T (1990) Induction of myelin-associated glycoprotein mRNA in experimental remyelination. Brain Res 513:152155.

Garcia-Fernandez LF, Rausell E, Urade Y, Hayaishi O, Bernal J, Munoz A (1997) Hypothyroidism alters the expression of prostaglandin $D_{2}$ synthase/beta trace in specific areas of the developing rat brain. Eur J Neurosci 9:1566-1573.

Gerashchenko DY, Beuckmann CT, Marcheselli VL, Gordon WC, Kanaoka Y, Eguchi N, Urade Y, Hayaishi O, Bazan NG (1998) Localization of lipocalin-type prostaglandin D synthase (beta-trace) in iris, ciliary body, and eye fluids. Invest Ophthalmol Vis Sci 39:198-203.

Gilg AG, Singh AK, Singh I (2000) Inducible nitric oxide synthase in the central nervous system of patients with X-adrenoleukodystrophy. J Neuropathol Exp Neurol 59:1063-1069.
Hayaishi O, Urade Y (2002) Prostaglandin $\mathrm{D}_{2}$ in sleep-wake regulation: Recent progress and perspectives. Neuroscientist 8:12-15.

Hirai H, Tanaka K, Yoshie O, Ogawa K, Kenmotsu K, Takamori Y, Ichimasa M, Sugamura K, Nakamura M, Takano S, Nagata K (2001) Prostaglandin $\mathrm{D}_{2}$ selectively induces chemotaxis in $\mathrm{T}$ helper type 2 cells, eosinophils, and basophils via seven-transmembrane receptor CRTH2. J Exp Med 193:255-261.

Hirata M, Kakizuka A, Aizawa M, Ushikubi F, Narumiya S (1994) Molecular characterization of a mouse prostaglandin D receptor and functional expression of the cloned gene. Proc Natl Acad Sci USA 91:11192-11196.

Igisu H, Suzuki K (1984a) Analysis of galactosylsphingosine (psychosine) in the brain. J Lipid Res 25:1000-1006.

Igisu H, Suzuki K (1984b) Progressive accumulation of toxic metabolite in a genetic leukodystrophy. Science 224:753-755.

Itoyama Y, Webster HD (1982) Immunocytochemical study of myelinassociated glycoprotein (MAG) and basic protein (BP) in acute experimental allergic encephalomyelitis (EAE). J Neuroimmunol 3:351-364

Kawahito Y, Kondo M, Tsubouchi Y, Hashiramoto A, Bishop-Bailey D, Inoue K, Kohno M, Yamada R, Hla T, Sano H (2000) 15-deoxy$\Delta^{12,14}-\mathrm{PGJ}_{2}$ induces synoviocyte apoptosis and suppresses adjuvantinduced arthritis in rats. J Clin Invest 106:189-197.

Kliewer SA, Lenhard JM, Willson TM, Patel I, Morris DC, Lehmann JM (1995) A prostaglandin $J_{2}$ metabolite binds peroxisome proliferatoractivated receptor gamma and promotes adipocyte differentiation. Cell 83:813-819.

Liu JS, Zhao ML, Brosnan CF, Lee SC (2001) Expression of inducible nitric oxide synthase and nitrotyrosine in multiple sclerosis lesions. Am J Pathol 158:2057-2066.

Ludwin SK (1979) The perineuronal satellite oligodendrocyte. A role in remyelination. Acta Neuropathol (Berl) 47:49-53.

Ludwin SK (1984) The function of perineuronal satellite oligodendrocytes: an immunohistochemical study. Neuropathol Appl Neurobiol 10:143-149.

Maesaka JK, Palaia T, Frese L, Fishbane S, Ragolia L (2001) Prostaglandin $\mathrm{D}_{2}$ synthase induces apoptosis in pig kidney LLC-PK1 cells. Kidney Int 60:1692-1698.

Minc-Golomb D, Tsarfaty I, Schwartz JP (1994) Expression of inducible nitric oxide synthase by neurones following exposure to endotoxin and cytokine. Br J Pharmacol 112:720-722.

Minc-Golomb D, Yadid G, Tsarfaty I, Resau JH, Schwartz JP (1996) In vivo expression of inducible nitric oxide synthase in cerebellar neurons. J Neurochem 66:1504-1509.

Mizoguchi A, Eguchi N, Kimura K, Kiyohara Y, Qu WM, Huang ZL, Mochizuki T, Lazarus M, Kobayashi T, Kaneko T, Narumiya S, Urade Y, Hayaishi O (2001) Dominant localization of prostaglandin D receptors on arachnoid trabecular cells in mouse basal forebrain and their involvement in the regulation of non-rapid eye movement sleep. Proc Natl Acad Sci USA 98:11674-11679.

Molina-Holgado E, Vela JM, Arevalo-Martin A, Guaza C (2001) LPS/ IFN- $\gamma$ cytotoxicity in oligodendroglial cells: role of nitric oxide and protection by the anti-inflammatory cytokine IL-10. Eur J Neurosci 13:493-502.

Morell P, Barrett CV, Mason JL, Toews AD, Hostettler JD, Knapp GW, Matsushima GK (1998) Gene expression in brain during cuprizoneinduced demyelination and remyelination. Mol Cell Neurosci 12:220227.

Nagoshi H, Uehara Y, Kanai F, Maeda S, Ogura T, Goto A, Toyo-oka T, Esumi H, Shimizu T, Omata M (1998) Prostaglandin D $D_{2}$ inhibits inducible nitric oxide synthase expression in rat vascular smooth muscle cells. Circ Res 82:204-209.

Padilla J, Kaur K, Cao HJ, Smith TJ, Phipps RP (2000) Peroxisome proliferator activator receptor-gamma agonists and 15-deoxy- $\Delta^{12,14}$ $\mathrm{PGJ}_{2}$ induce apoptosis in normal and malignant B- lineage cells. J Immunol 165:6941-6948.

Ragolia L, Palaia T, Frese L, Fishbane S, Maesaka JK (2001) Prostaglandin $\mathrm{D}_{2}$ synthase induces apoptosis in PC12 neuronal cells. NeuroReport 12:2623-2628.

Rodriguez M, Prayoonwiwat N, Howe C, Sanborn K (1994) Proteolipid protein gene expression in demyelination and remyelination of the central nervous system: a model for multiple sclerosis. J Neuropathol Exp Neurol 53:136-143.

Rohn TT, Wong SM, Cotman CW, Cribbs DH (2001) 15-deoxy- $\Delta^{12,14}$ prostaglandin $\mathrm{J}_{2}$, a specific ligand for peroxisome proliferator-activated receptor- $\gamma$, induces neuronal apoptosis. NeuroReport 12:839-843.

Sakai N, Inui K, Tatsumi N, Fukushima H, Nishigaki T, Taniike M, Nishimoto J, Tsukamoto H, Yanagihara I, Ozono K, Okada S (1996) Molecular cloning and expression of cDNA for murine galactocerebrosidase and mutation analysis of the twitcher mouse, a model of Krabbe's disease. J Neurochem 66:1118-1124.

Sato I, Himi T, Murota S (1996) Lipopolysaccharide-induced nitric oxide synthase activity in cultured cerebellar granule neurons. Neurosci Lett 205:45-48.

Sotelo C, Palay SL (1971) Altered axons and axon terminals in the 
lateral vestibular nucleus of the rat. Possible example of axonal remodeling. Lab Invest 25:653-671.

Suzuki K, Taniike M (1995) Murine model of genetic demyelinating disease: the twitcher mouse. Microsc Res Tech 32:204-214.

Taniike M, Suzuki K (1994) Spacio-temporal progression of demyelination in twitcher mouse: with clinico-pathological correlation. Acta Neuropathol 88:228-236.

Taniike M, Suzuki K (1995) Proliferative capacity of oligodendrocytes in the demyelinating twitcher spinal cord. J Neurosci Res 40:325-332.

Taniike M, Marcus JR, Nishigaki T, Fujita N, Popko B, Suzuki K (1998) Suppressed UDP-galactose: ceramide galactosyltransferase and myelin protein mRNA in twitcher mouse brain. J Neurosci Res 51:536-540.

Taniike M, Mohri I, Eguchi N, Irikura D, Urade Y, Okada S, Suzuki K (1999) An apoptotic depletion of oligodendrocytes in the twitcher, a murine model of globoid cell leukodystrophy. J Neuropathol Exp Neurol 58:644-653.

Tansey FA, Cammer W (1991) A pi form of glutathione-S-transferase is a myelin- and oligodendrocyte-associated enzyme in mouse brain. J Neurochem 57:95-102.

Tansey FA, Zhang H, Cammer W (1996) Expression of carbonic anhydrase II mRNA and protein in oligodendrocytes during toxic demyelination in the young adult mouse. Neurochem Res 21:411-416.

Toh H, Kubodera H, Nakajima N, Sekiya T, Eguchi N, Tanaka T, Urade Y, Hayaishi O (1996) Glutathione-independent prostaglandin D synthase as a lead molecule for designing new functional proteins. Protein Eng 9:1067-1082.

Toyooka K, Fujimura H, Yoshikawa H, Taniike M, Inui K, Yorifuji S, Tarui S, Okada S, Yanagihara T (1993) Nephrosialidosis: ultrastructural and lectin histochemical study. Acta Neuropathol 86:198-205.

Ujihara M, Urade Y, Eguchi N, Hayashi H, Ikai K, Hayaishi O (1988) Prostaglandin $\mathrm{D}_{2}$ formation and characterization of its synthetases in various tissues of adult rats. Arch Biochem Biophys 260:521-531.

Urade Y, Hayaishi O (1999) Prostaglandin $D_{2}$ and sleep regulation. Biochim Biophys Acta 1436:606-615.

Urade Y, Hayaishi O (2000a) Biochemical, structural, genetic, physio- logical, and pathophysiological features of lipocalin-type prostaglandin D synthase. Biochim Biophys Acta 1482:259-271.

Urade Y, Hayaishi O (2000b) Prostaglandin D synthase: structure and function. Vitam Horm 58:89-120.

Urade Y, Fujimoto N, Hayaishi O (1985a) Purification and characterization of rat brain prostaglandin D synthetase. J Biol Chem 260:12410-12415.

Urade Y, Kaneko T, Fujimoto N, Konishi A, Mizuno N, Hayaishi O (1985b) Immunohistochemical localization of prostaglandin D synthase in oligodendrocytes in the central nervous system of adult rat. In: Dynamic properties of glia cells II. Cellular and molecular aspects (Grisar T, Franck G, Hertz L, Norton WT, Sensenbrenner, Woodbury DM, eds), pp 131-132. New York: McGraw-Hill.

Urade Y, Fujimoto N, Kaneko T, Konishi A, Mizuno N, Hayaishi O (1987) Postnatal changes in the localization of prostaglandin D synthetase from neurons to oligodendrocytes in the rat brain. J Biol Chem 262:15132-15136.

Urade Y, Kitahama K, Ohishi H, Kaneko T, Mizuno N, Hayaishi O (1993) Dominant expression of mRNA for prostaglandin D synthase in leptomeninges, choroid plexus, and oligodendrocytes of the adult rat brain. Proc Natl Acad Sci USA 90:9070-9074.

Wenger D, Suzuki K, Suzuki Y, Suzuki K (2000) Galactosylceramidase lipidosis: globoid-cell leukodystrophy (Krabbe disease). In: The metabolic and molecular bases of inherited disease (Scriver C, Beaudet A, Sly W, Valle D, Chids B, Kinzler K, Vogelstein B, eds), pp 3669-3694. New York: McGraw-Hill.

Wu YP, Matsuda J, Kubota A, Suzuki K, Suzuki K (2000) Infiltration of hematogenous lineage cells into the demyelinating central nervous system of twitcher mice. J Neuropathol Exp Neurol 59:628-639.

Yao DL, Liu X, Hudson LD, Webster HD (1995) Insulin-like growth factor I treatment reduces demyelination and up-regulates gene expression of myelin-related proteins in experimental autoimmune encephalomyelitis. Proc Natl Acad Sci USA 92:6190-6194.

Yoshioka A, Shimizu Y, Hirose G, Kitasato H, Pleasure D (1998) Cyclic AMP-elevating agents prevent oligodendroglial excitotoxicity. J Neurochem 70:2416-2423. 